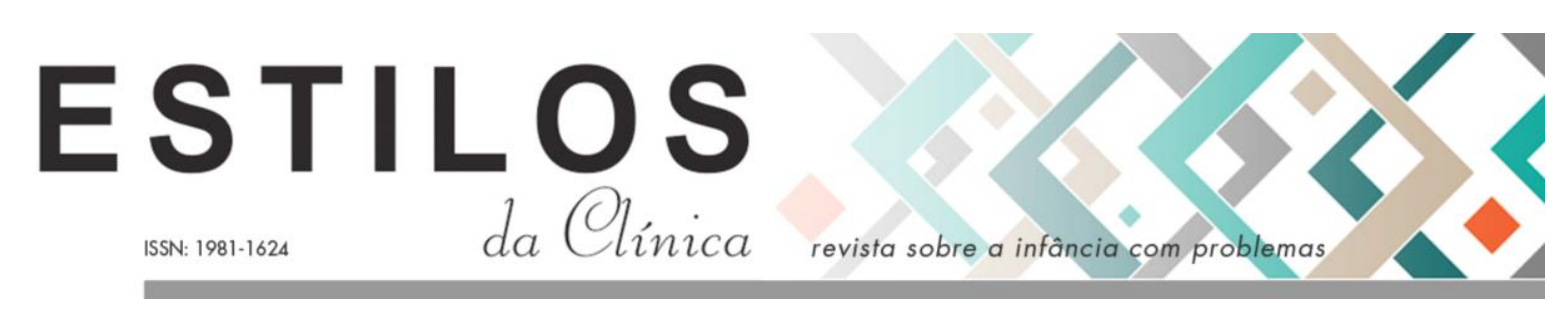

DOI: https://doi.org/10.11606/issn.1981-1624.v24i2p291-303.

\title{
Artigo
}

\section{Automutilações na adolescência e suas narrativas em contexto escolar}

\author{
Autores: Lorena da Silva Lopes; Leônia Cavalcante Teixeira
}

Resumo. O artigo tem por objetivo discutir a automutilação e suas narrativas por adolescentes em contexto escolar. Trata-se de uma pesquisa que envolve a psicanálise e o campo da educação, como um trabalho possível da clínica institucional. A partir de estudos de casos de uma escola privada em Fortaleza, são discutidos os seguintes aspectos: autolesão e os efeitos na escola, conflitos socio-familiares e processo de subjetivação adolescente. Conclui-se que a partir de uma escuta qualificada na escola é possível dar voz aos adolescentes para que possam produzir um saber sobre si, e ao seu modo sustentar seu mal estar.

Palavras-chave: automutilação; adolescência; escola; psicanálise.

\section{Automutilaciones en la adolescencia y sus narrativas en contexto escolar}

Resumen. El artículo tiene por objetivo discutir la automutilación y sus narrativas por adolescentes en contexto escolar. Se trata de una investigación que involucra el psicoanálisis y el campo de la educación, como un trabajo posible de la clínica institucional. A partir de estudios de casos de una escuela privada en Fortaleza, se discuten los siguientes aspectos: autolesión y los efectos en la escuela, conflictos socio-familiares y proceso de subjetivación adolescente. Se concluye que a partir de una escucha cualificada en la escuela es posible dar voz a los adolescentes para que puedan producir un saber sobre sí, ya su modo sostener su malestar.

Palabras clave: automutilación; adolescencia; escuela; psicoanálisis.

\section{Self-mutilation in adolescence and its narratives in school context}

Abstract. The article aims to discuss self - mutilation and its narratives by adolescents in a school context. It is a research that involves psychoanalysis and the field of education as a possible work of the institutional clinic. From the case studies of a private school in Fortaleza, the following aspects are discussed: self-harm and effects in school, socio-familial conflicts and adolescents subjectivation process. It is concluded that from a qualified listening in the school it is possible to give voice to the adolescents so that they can produce a knowledge about themselves, and in their way to sustain their malaise.

Keywords: self-mutilation; adolescence; school; psychoanalysis.

1. Psicóloga escolar, Universidade de Fortaleza, Fortaleza, CE, Brasil, E-mail: lorenaslopes21@gmail.com

2. Professora Doutora, Universidade de Fortaleza, Fortaleza, CE, Brasil, E-mail: leonia.ct@gmail.com 
E te artigo versa acerca do adolescer e de uma de suas vicissitudes na atualidade, qual seja a prática de automutilações. Não que seja própria à adolescência, mas que a tomamos como um fenômeno que chama a atenção de várias especialidades e que toca a nós, psicanalistas, por dizer do adolescer como passagem e do trabalho psíquico que deixa marcas quanto ao encontro com o sexo, a morte e Lei.

A adolescência não consistiu em um objeto da psicanálise, mas o sujeito adolescente sim, já que é o sujeito do inconsciente que aí se coloca. Como momento lógico e não cronológico, a adolescência é aqui problematizada a partir de um caso construído pela escuta de uma adolescente em contexto institucional escolar. Assim, este trabalho ratifica a psicanálise em extensão, tal qual pensada por Lacan (2003) e seus efeitos para o sujeito e o social.

Desprender-se do universo familiar é uma das tarefas que compete ao adolescente, mas este recorre aos recursos que a sociedade lhe oferece, de acordo com seus ditames. É a tarefa de confrontar-se com o deslocamento da autoridade e com uma tensão resultante dos anseios egoístas e altruístas - tensão que mostra, portanto, a passagem de um ensimesmamento autoerógeno a uma escolha objetal pautada pela alteridade (Marcos \& Mendonça, 2018; Matheus, 2007; Reymundo, 2016).

O processo de subjetivação do adolescente, ao realizar esse desprendimento dos pais, concretiza-se como uma forma de colocar-se como sujeito singular, capaz de viver ao seu modo, utilizando recursos que lhes são satisfatórios, para então conquistar a sua maneira de atuar no mundo atravessado por condutas e valores que lhe condiz.

$\mathrm{Na}$ adolescência há uma tendência maior do agir do que a utilização de outros recursos como a palavra, ou seja, no lugar de colocar em palavras aquilo que o angustia, o adolescente transfere para o corpo, que é a forma de percebê-lo como sendo seu. Essa tendência "é muitas vezes compreendida como um fenômeno que vem em resposta à descoberta das percepções corporais no adolescente, segundo às quais seu corpo se torna um estranho" (Alberti, 2009, p. 26).

Nock (2010) afirma que, comumente, a automutilação inicia-se na adolescência e é mais prevalente em adolescentes e adultos jovens, sobretudo do gênero feminino, o que justifica os estudos terem como população-alvo estes grupos. Além disso, destaca que é mais frequente ocorrer em situação privada com a utilização de um objeto afiado para cortar a pele ou pontiagudo para desenhar ou escrever sobre a superfície do corpo e que há variação tanto em relação à frequência quanto à severidade da automutilação entre as pessoas estudadas.

A questão da automutilação por adolescentes consiste em objeto de muitos estudos, como os de Cedaro \& Nascimento (2013), Lorena (2016), Jatobá (2010), Jorge, Queiroz, \& Saraiva (2015), Monteiro, Bahia, Paiva, Sá, \& Minayo (2015) e Silva (2012), no entanto, as pesquisas que envolvem essa questão atrelada ao contexto escolar ainda são insuficientes.

Escolhemos o termo automutilação por ser uma nomenclatura mais encontrada em estudos brasileiros. Outras formas de nomear são: lesão autoprovocada, autolesão, autoagressão (Bernardes, 2015). Ainda em estudos no campo da autoincisão fala-se muito na prática do cutting. Le Breton (2003) em seu estudo "La peau et la trace: sur les blessures de soi" discute sobre a cirurgia auto-sensorial, a arte corporal e a forma como o sujeito administra o apaziguamento quando pratica os cortes em si mesmo.

O comportamento automutilante impulsivo envolve condutas que incluem cortar a própria pele, queimar-se e bater-se (Giusti,Garreto,\& Scivoletto, 2008). Os comportamentos de automutilação, geralmente, estão atrelados às relações primeiras do sujeito com o Outro e o 
conflito que se dá entre eles; a partir da internalização desse tipo de relação, o adolescente inflige dor a si mesmo.

Sabemos que a psicanálise e educação são áreas que divergem quanto à noção de sujeito por terem embasamentos teórico-epistemológicos diferentes, mas que mesmo as tensões entre ambas podem ser produtivas quando tomamos a psicanálise e as implicações que traz à abordagem da instituição escola como norteadora da atuação do psicólogo. No nosso caso, assumir a perspectiva de ressaltar a singularidade do sujeito-adolescente como diretriz do trabalho do psicólogo escolar permite que a escola seja um lugar possível para a subjetivação.

Geoffroy e Alberti (2015) entendem que na escola pode ser criado um espaço também de fala, e de interlocução com o objetivo de resgatar a dimensão do desejo na ação educativa e promover o reposicionamento do sujeito, para que suas queixas sejam possibilidade de produção de um saber que lhe seja próprio.Para isso é necessário garantir um espaço de escuta que seja sigiloso.

Com relação às bases metodológicas para o delineamento do artigo utilizamos a pesquisa em psicanálise (Costa, Martinez, Banhos, Pinheiro, Teixeira \& Pinheiro, 2015; Oliveira \& Tafuri, 2012), como fio condutor, percebendo que há nela algo próprio no fazer pesquisa tendo em vista a consideração do singular como primordial ao se referir ao sujeito; o objeto em psicanálise, por exemplo, nunca se deixa ser reconhecido totalmente, pois sua origem é sempre o inconsciente (Oliveira \& Tafuri, 2012).

Foram realizados alguns encontros com a adolescente, que denominamos de escuta clínica na instituição escola. Em nossos encontros, permitimos que a adolescente associasse livremente, deixando claro que ela poderia falar de sua angústia e o que estava lhe incomodando. Nomeamos encontro junto à adolescente, caracterizando a disponibilidade de escuta, ratificando a premissa de que, quando ofertada a escuta, a demanda, de alguma, forma advém (Lacan, 1999).

O presente estudo teve como objetivo analisar a automutilação de adolescentes e como essas narrativas aparecem no contexto escolar, qualificadas pelos efeitos da escuta clínica institucional (Rosa, 2004). Apresentaremos a vinheta construída a partir da escuta de uma adolescente nomeada de Laura, para depois analisarmos os efeitos da automutilação no espaço escolar.

\section{Laura: os efeitos do ato no espaço escolar}

Laura tinha 16 anos, fazia o $9^{\circ}$ ano do ensino fundamental II. Procurou a nova escola na tentativa de ser acolhida, pois na instituição anterior sofria bullying. Ela relatou que jogavam a sua mochila pela janela, amarravam seus sapatos na carteira, apelidavam-na como a louca da sala, diziam que ela sempre queria "se mostrar" por gostar de participar das aulas. Ela chegou à escola em que desenvolvemos este estudo com a queixa de grave ansiedade, pânico escolar e sintomas depressivos.

Trouxe o laudo médico que indicava o uso de medicações e a solicitação para substituir as avaliações escritas por trabalhos, realizados em sala de aula, relacionados com os conteúdos que fossem vistos. A ida na escola tornava-se muitas vezes um horror para Laura, por vezes não tinha o sentimento de pertença, sentia-se sozinha e devido a estas insatisfações sempre estava com o braço cortado, por ter praticado a automutilação. No laudo psiquiátrico ainda constava o pedido de dispensa das possíveis faltas que a aluna viesse a ter por conta do seu quadro psicopatológico. 
Apesar de ela não se enquadrar às normas da escola como fazer os testes, entrar na sala no horário certo, Laura apresentava clareza de pensamento, sendo consciente de suas dificuldades e possibilidades. A adolescente, na maioria do tempo, ficava lendo livros na coordenação da escola. Ela apreciava leituras sobre psiquiatria e estudos acerca do cérebro e questões neuronais, construindo um rico discurso sobre o que acontecia consigo. Laura era acompanhada por psiquiatra e fazia psicoterapia.

Nos contatos com a psicóloga da escola, Laura relatou que realizara cortes nos pulsos pelo menos 15 vezes, relacionando isso às 15 vezes que seu pai a abandonou - dado que atribui ter descoberto na psicoterapia. Com 13 anos foi diagnosticada com transtorno bipolar atrelado à depressão e esse foi o período em que executara as tentativas de suicídio e, aos 15 anos, o diagnóstico foi mudado para transtorno borderline. Quanto aos familiares, seus pais eram separados e seu pai já havia morado um tempo fora do país. Sua família é de origem francesa e Laura gostava de se vestir à moda francesa - bohème, assim dizia. Ela demonstrava desejo de acrescentar, ao seu sobrenome, o sobrenome francês de sua mãe. As vezes em que Laura mencionou o nome do pai relatava sentimento de ambivalência, por querer um distanciamento e ao mesmo tempo uma aproximação. Na escola, o lugar em que menos ficava era em sala de aula, apesar de ser uma aluna bastante participativa quando comparecia à escola. Em função das crises de depressão diagnosticadas pelo psiquiatra de referência, ela recomeçou o ano duas vezes, pois abandonou o período letivo na metade. Laura pintava vários quadros para expressar como se sentia em relação à doença, como nomeava seu estado. Dizia gostar do vermelho e de cores fortes quando estava muito ativa, do azul quando estava tranquila e do preto, cor associada à depressão por ela, quando não estava bem. Numa tentativa de suportar a escola, Laura encontrava artifícios, como, por exemplo, vir à paisana em vez de uniforme. Ela diz se sentir melhor quando não está sob o enquadramento normativo da escola. Pelos contatos com a mãe de Laura, quando esta foi convidada a comparecer ao serviço de psicologia, ficou a impressão de que esta legitimava o diagnóstico do médico e de que buscava esconder/proteger a filha denominando-a como superior em relação as outras adolescentes da mesma idade. Já o pai dizia não acreditar que ela pudesse estar com dificuldades e problemas na escola e, principalmente, em relação ao seu processo de adolescer, já que a filha sempre foi inteligente. A atitude do pai era brigar com Laura obrigando-a a frequentar a escola todos os dias. Laura encontrava espaços de vida na escola, por esta ter uma filosofia inclusiva quanto às peculiaridades dos discentes, possibilitando modalidades alternativas de ensino, de avaliação, de disciplina e de acompanhamento para cada caso. Infelizmente Laura saiu da instituição escolar e, nos últimos encontros com a psicóloga, relatou que o pai devia inúmeros meses de pensão alimentícia podendo ser preso.

\section{À escuta do sofrimento que marca o corpo}

Considerando as automutilações, Alberti (2009) entende que os adolescentes utilizam de mutilações para expressar aquilo que não pode ser dito através de palavras, sendo uma forma de denúncia do próprio sofrimento. O corpo, nesta perspectiva, funciona como meio de comunicar aquilo que lhes sufocam. Utilizando-se das palavras, ou seja, quando o significante representa algo para outro significante através de uma cadeia, o simbólico reveste e é possível, então, que o adolescente possa se direcionar para outros processos construtivos que não seja o ato de se automutilar. Apesar de entendermos ser o ato de cortar-se uma forma também de estabilização, o sujeito, poderia encontrar através da sublimação, outras formas de 
expressões daquilo que lhe atormenta. A autora salienta que na adolescência há uma tendência maior do agir do que a utilização de outros recursos como a palavra, ou seja, no lugar de colocar em palavras aquilo que o angustia, o adolescente transfere para o corpo, qual forma de percebê-lo como sendo seu. Essa tendência "é muitas vezes compreendida como um fenômeno que vem em resposta à descoberta das percepções corporais no adolescente, segundo as quais seu corpo se torna um estranho" (Alberti, 2009, p. 26).

Freud (1926/1976), ao falar da experiência corporal nos sujeitos, entende que esse fato pode envolver processos complexos de investimentos, desinvestimentos e reinvestimentos narcísicos, movimentos pulsionais eróticos e tanáticos que reinscrevem o sujeito nos momentos lógicos do autoerotismo e do narcisismo. Isso resulta em posições subjetivas arcaicas que levam a posições masoquistas centradas no gozar e não na lógica do desejo (Lacan, 1972-1973/1985).

Em relação ao modo como o sujeito marca o corpo na tentativa de subjetivar-se, Lacan (1972-1973/1985) supõe que há nessa marca, por exemplo, na escarificação, a tendência para o narcisismo secundário, uma vez que existe um retorno da libido para o eu, exercendo uma dinâmica auto-erótica através do gozo no sofrimento no ato de marcar. A marca feita pelo sujeito tem uma função de ser para o Outro, e uma função extremamente erótica (Lacan, 1964/1995b). Para Fernandes (2010), a escarificação é uma das manifestações clínicas que nos faz perceber o quanto a libido pode ser mortífera, fazendo-se verificar que a libido também pode ser pensada como associada à pulsão de morte.

Os cortes no corpo podem ser percebidos, também, por uma tentativa de evitar a castração; nesse sentido, Lacan (1972-1973/1985) os relaciona como a impossibilidade da relação sexual. Diante do real do sexo, os adolescentes ficam paralisados, estagnados, de modo que passa a ser confuso e ambivalente a ideia de poder se relacionar sexualmente com o outro. Por eximir de si mesmo o dizer, afastando tudo que lhe amedronta da consciência, o adolescente transfere para o corpo tudo aquilo que não pode ser dito por ele naquele momento.

Rosa (2009) salienta que "o não-dito é um dizer que vem do lugar que se deve calar. Esse calar faz ponte com a Lei, que representa o limite imposto à onipotência do desejo e que irá remeter ao campo do Outro" (p. 23). Em outras palavras, o não-dito está relacionado com a castração, na medida em que o sujeito deseja, mas é barrado por uma Lei, que lhe adverte no seu dizer e no seu fazer.

Os comportamentos de automutilação, geralmente, estão atrelados às relações primeiras do sujeito com o Outro e o conflito que se dá entre eles; a partir da internalização desse tipo de relação, o adolescente inflige dor a si mesmo. Fortes e Macedo (2017) trabalham com a noção de arrefecimento na relação com o outro tornando umas das marcas cruciais do padecimento psíquico contemporâneo, salientam que o ato mutilatório funciona como um recurso apaziguante para uma dor que não encontra expressão pela via das palavras.

\section{A escola à escuta do sujeito adolescente: uma convocação do olhar do Outro}

O lugar da escuta analítica, nas instituições ou âmbito coletivo, perpassa, sobretudo, por um mal-estar que demanda do analista uma intervenção. Desse modo, o analista é convocado a ocupar dois lugares: o lugar do fazer-dizer, em que o analista facilitará a circulação discursiva e a função do escriba, onde por situações pontuais o analista realiza alguma comunicação àqueles que solicitaram a intervenção (Stazzone, 1997). Assim é possível a 
construção de hipóteses à luz de diversas revisões teóricas e nas sucessivas reuniões com o grupo de pessoas da instituição na qual se está intervindo.

Um exemplo da atuação da escuta analítica nas instituições pode ser evidenciado quando procura-se trabalhar, analiticamente, escutando várias pessoas ao mesmo tempo, identificando a repetição de uma palavra ou expressão. Isso dá lugar a uma intervenção que tende a produzir uma mudança de sentido, onde o que está em jogo é saber em qual discurso se situam os enlaces das instituições (Stazzone, 1997).

Retornando ao objetivo deste artigo, no qual, nos propomos a apresentar de que maneira as narrativas de automutilação aparecem no contexto escolar e quais os efeitos delas para a escola, queremos destacar como essa demanda é dirigida à instituição. Tendo em vista, que é oferecida uma escuta qualificada no contexto escolar, onde muitas questões de caráter emocional aprecem ao setor de psicologia, dentre elas, a automutilação. O sintoma da automutilação na escola, pode gerar consequências graves para o sujeito e instituição, no que diz respeito a um certo tipo de paralisação nas produções, dificuldade de socialização e inadequação ao espaço escolar.

Vemos que as instituições, que abrem espaço para essa escuta consegue positivamente um diálogo mais aberto com os alunos, considerando não só os aspectos cognitivos, mas, sobretudo as questões emocionais que influenciam diretamente na aprendizagem.

$\mathrm{Na}$ escola, os sintomas da adolescência aparecem disfarçados pelo nome de ansiedade, transtorno borderline, dislexia, depressão; mas, na verdade, o que encontramos com mais frequência são sujeitos que expressam seu mal-estar através do corpo, por isso os casos tão comuns de automutilação, sobretudo em meninas. Os professores, na maioria das vezes, são convocados a responderem essas demandas ditas psicológicas e, de alguma forma a lidar com esses sintomas, no entanto, eles se veem paralisados e sem saber como agir. Há certa incoerência porque, de um lado, os professores são cobrados pela direção a elaborar práticas que incluam (aprendizagem significativa, considerar o erro etc.) e, de outro, precisam concluir conteúdos extensos ao término de um ano. Esse é um dos exemplos de incômodo do professor ao ter que lidar com esses impasses.

Escutar um adolescente com comportamento autolesivo, por exemplo, e perceber que naquele momento ele não está sendo capaz de fazer outro movimento para suas insatisfações, é considerar de forma sutil o seu sofrimento, adequando-o a um currículo adaptado, abrindo exceções para que ele possa transitar por outros espaços da escola que não só a sala de aula, seja uma biblioteca, sala de artes ou de música; para que possa acolher minimamente o malestar daquele sujeito, não só o enquadrando no modelo que se coloca como ideal.

Rassial (1997b) entende que a adolescência transtorna o eu e os ideais. Isso ocorre porque, com as transformações da puberdade, esse adolescente é visto pelo olhar do Outro social como o desajeitado. Além disso, há por parte da família um olhar atravessado, mas, apesar de todas estas querelas, os jovens se constituem em direção ao social. A saída do lar familiar para produzir laços sociais exige, assim, construções identificatórias.

As automutilações podem funcionar como acting-out, ou seja, como uma demanda endereçada ao Outro, pois os cortes no corpo nem sempre são efetivados com a intenção de pôr fim à vida. Existe uma linha tênue, que ainda o faz demandar algo, diferentemente dos casos que acontece o suicídio, onde há, de fato, um curto-circuito e o sujeito não demanda mais o seu objeto, não se endereça ao Outro.

Nos adolescentes que praticam a automutilação existe algo que convoca o olhar do Outro para o seu corte, apesar da tentativa de escondê-los, por exemplo, com pulseiras ou faixas. Faz-se um convite ao olhar para saber o que está por trás de tais adereços. Nesse sentido, há 
sempre algo que escapa; é um esconder, mas que não esconde totalmente. Le Breton (2007) destacou que as marcas corporais implicam em uma vontade de atrair o olhar, de fabricar uma estética de presença; é muitas vezes vivida como reapropriação do corpo e do mundo que em algum momento da vida se deixou escapar.

Moreira, Teixeira e Nicolau (2010) chamaram de meio de comunicação a forma como o sujeito utiliza o corpo para exteriorizar seus afetos, fantasias e desejos. Algo de ordem inconsciente transmite, por meio do corpo, as marcas e escarificações; assim, o corpo é o interlocutor das angústias que o sujeito não consegue colocar em palavras.

\section{A escuta de Laura}

No caso de Laura, percebemos nitidamente o quanto o valor da biomedicina opera, tanto no discurso da mãe quanto no discurso da própria Laura, que faz jus ao diagnóstico que lhe foi concedido, nomeando ter passado de um diagnóstico de bipolar para borderline. São presentes as várias tentativas da mãe de Laura para sabotar a escola, no sentido de considerar e reconsiderar o discurso médico como trazendo eixo e fazendo sentido para a família. Sem o diagnóstico é como se essa família se desorganizasse ainda mais, é como se a mãe precisasse desse diagnóstico médico e outorgante de um lugar para a filha, para continuar vivendo. Observa-se isto quando a mãe de Laura traz para a escola vários atestados médicos com indicação do que é para ser realizado na escola. Nesse sentido, consideramos válido destacar o quanto cada vez mais tanto a escola quanto a família acabam por entrar numa lógica biomédica sem questionar, por exemplo, por que o médico está indicando que a adolescente se ausente de sala de aula? Será que o psiquiatra conhece a realidade escolar? Alguma vez já visitou a escola? Conversou com os profissionais? Nesse sentido, como psicóloga da instituição, fazemos esse tipo de intervenção, para que não entremos na lógica desmedida de diagnósticos que atualmente são tão rápidos de serem dados como também são na mesma velocidade para serem retirados, ou seja, é preciso questionar a medicalização da vida, e os exacerbados diagnósticos.

Nessas circunstâncias, pensamos no que Ceccarelli (2010) apresentou como conceito de patologização da normalidade, entendida como toda forma discursiva geradora de regras sociais e normas de conduta que são utilizadas para classificar, etiquetar e às vezes punir. Essas regras determinam como os sujeitos devem proceder a partir de parâmetros que, na maioria das vezes, não levam em conta a particularidade da dinâmica pulsional do sujeito em questão. Será então que estamos entrando na lógica de uma patologização da existência? Onde todos precisam ser classificados, categorizados e medicados?

Pensamos que o modo de marcar o corpo que Laura encontrou seja para demarcar uma falta paterna que ocorre em sua história. O abandono é (re) escrito no corpo na tentativa de se fazer inscrever um pai que, mesmo ausente, revive em seu corpo, em sua pele. O corte em Laura não cessa de se inscrever, assim como a função paterna não cessa de ser clamada e inscrita na forma de traço a todo instante.

Reis (2018) destaca que a automutilação representa uma operação de corte, de descontinuidade, uma espécie de hiato no registro simbólico, que tem como fundamento primordial a angústia. Onde deveria aparecer o significante primordial do sujeito, surge a descontinuidade simbólica, a falta de significação subjetiva. Este autor ainda teoriza sobre uma questão central da contemporaneidade que é o fato dos sujeitos se encontrarem num estado "desbussolamento", ou seja, um homem perdido, desnorteado, isso se ver mais 
claramente na adolescência, onde os sujeitos nada têm a dizer sobre sua dor, por vezes não sabem o que querem da vida, nem sabe se querem alguma coisa, falta desejo!

Existe uma questão presente no Caso Laura, que é a forma como a família pensa e se articula em relação ao dinheiro. Tanto por parte de Laura como de sua mãe, há a súplica e lamúria para o pai de cobrança da pensão, a qual, pode dizer do desejo de Laura para trazer de volta a figura paterna, de convocar esse pai que se encontra ausente. A forma que mãe e filha encontraram para convocar esse pai foi através da cobrança: a mãe cobra o dinheiro da pensão e Laura cobra sua presença pela cobrança de uma dívida que atribui ao pai ter com ela. Laura, em outro momento, ainda legitima o poder que a mãe tem de dar voz de prisão ao pai, essa mãe que para ela é completa, toda poderosa. Pensamos ainda no dinheiro relacionado à dívida. Apesar de na realidade ser o pai o devedor da pensão, o que Laura deve ao pai? Qual o preço que ela paga para convocá-lo, clamar sua atenção, cortar-se em decorrência dos tantos abandonos mencionados?

Freud (1913/1996e) afirma que "poderosos fatores sexuais acham-se envolvidos no valor que é atribuído ao dinheiro" (p. 146). Para ele, as questões que envolvem dinheiro são tratadas da mesma maneira que as questões sexuais - com a mesma incoerência, pudor e hipocrisia. Tal aproximação entre o dinheiro e a sexualidade leva à constatação de que o dinheiro é libidinal, de que está ligado à obtenção de uma satisfação. Freud (1913/1996e) percebe que o sintoma é caro para o sujeito e passa a se interessar em saber como a doença e, particularmente, o sintoma poderiam ser amoedados pelo dinheiro. O sujeito tem satisfação com seu sintoma e, ao constatar isso, Freud fala em dois tipos de benefício, isto é, lucros na economia libidinal. O primeiro é o beneficio primário, que é ficar doente: da fuga para a doença se tira alguma vantagem. Já o segundo benefício ou ganho secundário deriva do primeiro e, através dele, tiram-se ainda mais vantagens da doença. O que Freud demonstra é que aquilo que parece ser evidente - retomar a saúde - não o é. Há alguma coisa entre a queixa, o sofrimento e o desejo de deixar essa condição que não é óbvia.

Podemos considerar que Laura quer de alguma maneira ter controle sobre o pai através do dinheiro e, assim, continuar com o seu sintoma (automutilação). Frequentemente vemos situações em que o modo como se lida com o dinheiro (ou com sua condição para obtê-lo) está alegoricamente marcado pelo sintoma, pela forma de organização subjetiva que cada um monta para si a partir da submissão à linguagem e ao campo do Outro (Hasky \& Frare, 2016).

Na escola, os resquícios do conflito em relação à Lei são evidenciados, uma vez que Laura questiona e transgride as normas e as regras, mostrando, muitas vezes, um pedido de limite e imposição. Nessa ocasião, trata-se de entender a adolescência sob o olhar do Outro, como observou Alberti (2009), indicando que há de existir a elaboração da falta do Outro, onde o adolescente precisará fazer o trabalho de separação que se torna inevitável para seu processo subjetivo. Neste veio, percebe-se que há uma alienação simbólica com o Outro, mas que, a posteriori, o sujeito supera a alienação buscando sua constituição psíquica.

Com efeito, as identificações na adolescência estão relacionadas a um processo de inscrição no Outro. Rassial (1999) discute a questão da identificação atrelada a processos repetitivos na adolescência, uma repetição no sentido mais arcaico do termo. Para esse autor, na adolescência há uma repetição de processos primeiros e que é "só-depois" (p.43), ou seja, é a posteriori que essas identificações produzirão efeitos, pois até a idade da adolescência essas questões ainda ficam suspensas.

Damous e Klautau (2016) estudaram a reatualização do trauma infantil sob o resultado da automutilação na adolescência, para as autoras as consequências do acontecimento traumático só se estabelecem a posteriori, e os atos repetitivos da automutilação, podem ocasionar uma 
compulsão a repetição em que há uma tentativa de elaboração de acontecimentos traumáticos vividos nos momentos inicias da constituição do psiquismo.

Na prática é feita uma demanda social ao adolescente para que ele não seja mais criança. Ele precisa, a qualquer custo, marcar o seu lugar no social. Confusos por não saberem bem onde se instalar, os adolescentes começam por se aproximar de grupos na tentativa de afirmação de lugares que, por vezes, estão marcados de ambivalência, pois talvez não fosse aquilo mesmo que os identificassem subjetivamente.

Quando o adolescente resolve atuar mutilando-se, por exemplo, há um contexto social e moral que diz: "não faça isso!", "porque você se corta?”. Existe no imaginário social uma falta de explicação ou, muito mais que isso, uma não justificativa para os cortes no corpo e, por vezes, os adolescentes são interpretados apenas como se estivessem chamando atenção.

$\mathrm{O}$ adolescente fica num jogo entre o supereu de origem parental e o supereu de origem coletiva. Nessa encruzilhada, transita pelas ordens proibitórias e ao mesmo tempo benevolentes da família e os interditos das leis sociais, percebendo, então, que a sua satisfação não será toda, mas somente parcial, quando pode, por exemplo, fazer um laço com o social (Rassial, 1997b).

No exercício de apreender e dar um lugar social a Laura e seu padecimento, pode-se entender que as automutilações podem funcionar como acting-out, uma vez que o adolescente faz um endereçamento ao Outro, pois os cortes no corpo nem sempre são efetivados com a intenção de pôr fim à vida. Existe uma linha tênue, que ainda o faz demandar algo, diferentemente dos casos onde existe o suicídio, onde acontece, de fato, um curto-circuito e o sujeito não demanda mais o seu objeto, não se endereça ao Outro.

Nos adolescentes que praticam a automutilação existe algo que convoca o olhar do Outro para o seu corte, apesar da tentativa de escondê-los, por exemplo, com pulseiras ou faixas. Faz-se um convite ao olhar para saber o que está por trás de tais adereços. Nesse sentido, há sempre algo que escapa; é um esconder, mas que não esconde totalmente. Le Breton (2007) destacou que as marcas corporais implicam em uma vontade de atrair o olhar, de fabricar uma estética de presença; é muitas vezes vivida como reapropriação do corpo e do mundo que em algum momento da vida se deixou escapar.

O corpo, muitas vezes, funciona como localização do mal-estar, pois é nele que são habitadas as angústias, tristezas e medos, que poderiam ser trabalhados através da fala; por isso é tantas vezes adoecido. A partir desta discussão, Freud (1926/1976) acentua o caráter do masoquismo como sendo compatível com posições centradas no gozar e não no desejo. As experiências que colocam o corpo como o centro integram processos complexos de investimentos e desinvestimentos; dessa forma, o sujeito circula pela lógica do narcisismo, adentrando em posições bem primitivas.

Pode-se fazer a pergunta básica para estes sujeitos: porque o corpo? Que tipo de linguagem os adolescentes utilizam que não é a linguagem falada, mas a linguagem atuada no corpo? Moreira, Teixeira e Nicolau (2010) chamaram de meio de comunicação a forma como o sujeito utiliza o corpo para exteriorizar seus afetos, fantasias e desejos. Algo de ordem inconsciente transmite por meio do corpo as marcas e escarificações; assim, o corpo é o interlocutor das angústias que o sujeito não consegue colocar em palavras.

Em geral, os adolescentes se unem a partir de grupos, identificam-se entre eles, e fazem valer uma espécie de pacto com o seu grupo social. Este pacto também é válido pelas marcas no corpo, identificam-se por ter praticado algum tipo de automutilação e se nomeiam das mais variadas formas. Existe uma filiação a grupos a partir das marcas corporais. Alguns 
adolescentes falam ainda de um vício, de ter experimentado se cortar depois de ter visto vídeos e imagens na internet e continuaram com a prática, sem conseguir mais parar.

Ao nos perguntarmos os motivos que levam uma adolescente a praticar automutilação, iremos perceber que existem os mais diversos: relação conflituosa com os pais, término de namoro, não está indo bem na escola, prazer em sentir a dor etc. No entanto, é preciso entender que a automutilação não pode ser vista somente do ponto de vista de algo que seja ruim e emitir um juízo de valor para com as pessoas que a praticam. Na maioria das vezes, as adolescentes que fazem a prática se valem dela como uma tentativa de estabilização, de algo que escapa à sua capacidade de conseguir lidar com os conflitos. É bem verdade que devemos ficar alertas para esse tipo de comportamento, pois, ao mesmo tempo em que a automutilação é uma forma de estabilização, pode ser que pela repetição o sujeito se fixe na pulsão de morte e ocorra o suicídio consumado.

Mieli (2002) considera que a intervenção voluntária sobre o real do corpo é uma espécie de necessidade, onde a manipulação irreversível é uma tentativa de dar estabilidade a uma forma que oscila e intervir em um traço físico particular do sujeito. A referida autora nomeou de punctum o lugar do próprio corpo percebido pelo sujeito como o que insiste no sentido de embaraçar. O punctum nesta perspectiva é o lugar do próprio corpo de onde os sentimentos são olhados. Em meninas que praticam a automutilação, diremos que o punctum seriam evidentemente os pulsos.

Trata- se de um embaraço que é ao mesmo tempo incômodo e impedimento dos movimentos; um estorvo, fonte de mal-estar e de perturbação. Tem-se vontade de se desfazer, de se aliviar desse lugar do corpo para dele se livrar. O punctum é um lugar do próprio corpo de onde nos sentimos olhados. O punctum, com frequência, concerne a um traço do contorno do corpo, da silhueta (Mieli, 2002, p. 15).

Mieli (2002) ainda designou que a intervenção irreversível no corpo, que ocorre por meio dos cortes, incisões de diferentes tipos, leva à constituição do landmark. Que trata-se de uma inscrição como apagamento e ao mesmo tempo como marco.

O landmark implica a invocação do traço, a procura de um corte simbólico que dá forma definida a um contorno flutuante, e envolve a suspensão de um olhar que torna sua própria forma vã. O landmark é indício de uma necessidade de uma inscrição simbólica representativa de um traço da função paterna, a ser distinguido de um traço paterno real. Nesse sentido, o landmark é porta-voz de uma intervenção na transmissão entre gerações (Mieli, 2002, p. 16).

Em outras palavras, entendemos que o lugar do corpo que a adolescente Laura escolhe para demarcar como sendo dela é um lugar designado para a escrita de si, onde são inscritos significantes de sua história individual, ao mesmo tempo em que podemos também perceber que os cortes da adolescente estão para além da palavra é algo da ordem do sem sentido e/ou do fora de sentido. Para Mieli (2002), essa é uma importante intervenção simbólica de transição para uma nova forma, como acontece nos rituais de passagem, em que uma transformação física autoriza a entrada no social, munida de identidade, atos e gestos.

\section{Considerações Finais}

Os comportamentos autolesivos na adolescência são revestidos de vários significados, é preciso sutileza na interpretação e análise de tais condutas. Portanto, salientamos que é fundamental considerar cada caso, como sendo único, cada um com sua história de vida 
diferente e com suas peculiaridades. Consideramos que no caso Laura havia a recusa pela palavra e, assim, analisamos pela via de uma possível falência do campo simbólico, dito de outro modo, havia uma substituição das palavras pela atuação no corpo através dos cortes realizados em si mesmo.

Acreditamos que através da possibilidade da escuta, as adolescentes possam se direcionar para um movimento criativo de conseguir, por exemplo, verbalizar as angústias e mal-estar através das palavras.

O psicólogo escolar, quando orientado pela psicanálise e sua ética, frente às narrativas da automutilação de adolescentes, como Laura, pode realizar um trabalho de propiciar um lugar de escuta diferenciada dos discursos normatizantes e engessados que comumente circulam pelos espaços educacionais. Acreditamos, que a escola pode sim, fazer resistência no modo de atuar, utilizando-se, por exemplo, de um viés clínico na instituição escolar e, compreender o sujeito para além de um "fracasso". Por isso, a importância do psicólogo escolar, retirar-se de sua sala, e circular pelos espaços, dá chance ao encontro, ao acaso, enxergar o novo.

\section{Referências}

Alberti, S. (2009). Esse sujeito adolescente (3a ed.). Rio de Janeiro: Rios Ambiciosos.

Bernardes, S. M. (2015). Tornar-se (in) visível: um estudo na rede de atenção psicossocial de adolescentes que se automutilam (dissertação de mestrado). Programa de Pós-Graduação em Saúde Mental e Atenção Psicossocial, Universidade Federal de Santa Catarina, Centro de Ciências da Saúde, Florianópolis, Santa Catarina. Recuperado de https://repositorio.ufsc.br/xmlui/handle/123456789/135810

Ceccarelli, P. R. (2010). A patologização da normalidade. Estudos de Psicanálise, (33), 125-136. Recuperado de http://pepsic.bvsalud.org/scielo.php?script=sci_arttext\&pid=S0100$34372010000100013 \& \operatorname{lng}=\mathrm{pt} \& \operatorname{lng}=\mathrm{pt}$.

Cedaro, J. J.\& do Nascimento, J. P. G. (2013). Dor e Gozo: relatos de mulheres jovens sobre automutilações. Psicologia USP, 24(2), 203-223.doi: https://dx.doi.org/10.1590/S010365642013000200002

Costa, T., Martinez, C. Banhos, T., Pinheiro, F., Teixeira, L.,\& Pinheiro, C. (2015). Considerações sobre a pesquisa em psicanálise e as posições sujeito $\mathrm{x}$ objeto do conhecimento. In L. Texeira, S. Rodrigues (Orgs.), A psicanálise nas searas da universidade, do direito, da arte e da literatura (pp. 31-39).Curitiba: Editora CRV.

Damous, Issa, \& Klautau, Perla. (2016). Marcas do infantil na adolescência: automutilação como atualização de traumas precoces. Tempo psicanalitico, 48(2), 95-113. Recuperado em 10 de março de 2019, de http://pepsic.bvsalud.org/scielo.php?script=sci_arttext\&pid=S0101$48382016000200007 \& \operatorname{lng}=$ pt\&tlng=pt.

Fernandes, A. H. (2010). Os efeitos da linguagem no corpo. In S. Carvalho (Org.), O mistério do corpo falante. Salvador: Associação Científica Campo Psicanalítico (pp. 19-26).

Fortes, I., \& Macedo, M. K. (2017). Automutilação na adolescência-rasuras na experiência de alteridade/Self-mutilation in adolescence-scratches in the otherness experience. Psicogente, 20(38). doi: http://doi.org/10.17081/psico.20.38.2556

Freud, S. (1976). Inibição, sintoma e ansiedade. In J. Strachey (Ed.), Edição Standard Brasileira das Obras Psicológicas Completas de Sigmund Freud (Vol. 20, pp. 95-204). Rio de Janeiro: Imago. (Originalmente publicado em 1926) 
Freud, S. (1996). Sobre o início do tratamento. In J. Strachey (Ed.), Edição Standard Brasileira das Obras Psicológicas Completas de Sigmund Freud (Vol. 12, pp. 139-158). Rio de Janeiro: Imago. (Originalmente publicado em 1913)

Geoffroy, R. M. G., \& Alberti, S. (2015). Contribuições de Jean Oury para verificar uma possível emergência do sujeito na escola. Estilos da Clínica, 20(2), 246-264. doi: http://dx.doi.org/10.11606/issn.1981-1624.v20i2p246-264

Giusti, J. S., Garreto, A. K. R.,\& Scivoletto, S. (2008). Automutilação. In C. N. Abreu, H.Tavares, \&T. A. Cordás (Orgs.), Manual clínico dos transtornos do controle dos impulsos (pp. 181-200). Porto Alegre: Artmed.

Hasky, F., \& Frare, A. P. (2016). A concessão de benefícios e a aposta na singularidade: um desafio para a Saúde Mental. Revista Latinoamericana de Psicopatologia Fundamental, 19(1), 99-113.doi: https://dx.doi.org/10.1590/1415-4714.2016v19n1p99.8

Jorge, J. C., Queirós, O., \& Saraiva, J. (2015). Descodificação dos comportamentos autolesivos sem intenção suicida: Estudo qualitativo das funções e significados na adolescência. Análise Psicológica, 33(2), 207-219.doi: https://dx.doi.org/10.14417/ap.991

Lacan, J. (1985). O Seminário, livro 20: Mais, ainda (1972-1973). Rio de Janeiro: Jorge Zahar.

Lacan, J. (1995). O Seminário, livro 11: Os quatro conceitos fundamentais da psicanálise (1964). Rio de Janeiro: Jorge Zahar.

Lacan, J. (1999). O Seminário: Livro 5: As formações do inconsciente (V. Ribeiro, Trad.). Rio de Janeiro: Jorge Zahar .(Originalmente publicado em 1957-1958).

Lacan, J. (2003). A proposição de 9 de outubro de 1967 (1967). Outros escritos. Rio de Janeiro: Jorge Zahar Editor.

Le Breton, D. (2003). La peau et la trace. Sur les blessures de soi. Paris: Métailié

Le Breton, D. (2007). Adeus ao corpo. Papirus Editora.

Lorena, R.G.S. (2016). Um corpo para (de) marcar-se: estudo psicanalítico acerca das escarificações na adolescência (dissertação de mestrado). Programa de Pós-Graduação em Psicologia Clínica Psicopatologia Fundamental e Psicanálise,Universidade Católica de Pernambuco, Recife. Recuperado de http://www.unicap.br/tede/tde_arquivos/1/TDE-2016-12-21T130027Z901/Publico/renata_guarana_sousa_lorena.pdf.

Marcos, C. M., \& Mendonça, R. L. (2018). Adolescência e diferença sexual. Estilos da Clínica, 23(1), 175-190. doi: https://doi.org/10.11606/issn.1981-1624.v23i1p175-190

Matheus, T. C. (2007). Adolescência: história e política do conceito na psicanálise. São Paulo: Casa do Psicólogo.

Mieli, P. (2002). Sobre as manipulações irreversíveis do corpo e outros textos psicanalíticos. Rio de Janeiro: Contra capa/Livraria do Corpo Freudiano de Rio de Janeiro.

Monteiro, A. R., Bahia, C. A., Anjos Paiva, E., de Sá, N. N. B., \& de Souza Minayo, M. C. (2015). Hospitalizações relacionadas a lesões autoprovocadas intencionalmente-Brasil, 2002 a 2013. Revista Ciência \& Saúde Coletiva, 20(3). doi: doi: 10.1590/1413-81232015203.16282014 Recuperado de http://www.scielosp.org/pdf/csc/v20n3/pt_1413-8123-csc-20-03-00689.pdf.

Moreira, J. D. O., Teixeira, L. C., \& Nicolau, R. D. F. (2010). Inscrições corporais: tatuagens, piercings e escarificações à luz da psicanálise. Revista Latinoamericana de Psicopatologia Fundamental, 13(4), 585-598.doi: https://dx.doi.org/10.1590/S1415-47142010000400004.

Nock, M.K. (2010). Self-Injury. Annual Review of Clinical Psychololgy, 6, 339-363. doi:10.1146/annurev.clinpsy.121208.131258 Recuperado de https://www.researchgate.net/profile/Matthew_Nock/publication/41654922_SelfInjury/links/00b7d533559937534b000000.pdf 
Oliveira, N. R., \& Tafuri, M. I. (2012). O método psicanalítico de pesquisa e a clínica: reflexões no contexto da Universidade. Revista Latinoamericana de Psicopatologia Fundamental, 15(4), 838.doi: https://dx.doi.org/10.1590/S1415-47142012000400007

Rassial, J. J. (1997). A adolescência como conceito da teoria psicanalítica.Adolescência: entre o passado e o futuro, 45-74. Porto Alegre: Artes e Ofícios.

Rassial, J. J. (1999). O adolescente e o psicanalista. Rio de Janeiro: Companhia de Freud.

Reis, M. N.(2018) Automutilação: o encontro entre o real do sofrimento e o sofrimento real. Polêm! ca, 18(1), 050-067. doi: https://doi.org/10.12957/polemica.2018.36069

Reymundo, O. (2016). Adolescências - tempo de compreender e posição sexuada. In H. Caldas (Org.), Errâncias, adolescências e outras estações.Belo Horizonte: Editora EBP.

Rosa, M. D. (2004). A pesquisa psicanalítica dos fenômenos sociais e políticos: metodologia e fundamentação teórica. Revista Mal-Estar e Subjetividade, 4(2), 329-348. Recuperado de http://www.redalyc.org/pdf/271/27140208.pdf.

Rosa, M. D. (2009). Histórias que não se contam: o não-dito e a psicanálise com crianças e adolescentes. São Paulo: Casa do Psicólogo.

Silva, E. M. A. (2012). Relações íntimas, regulação emocional e ferimentos autoinfligidos em estudantes universitários(dissertação de mestrado). Departamento de Psicologia Clínica, Universidade do Minho, Portugal. Recuperado de https://repositorium.sdum.uminho.pt/bitstream/1822/21240/1/Eliana\%20Marisa\%20Ara\%c3\%bajo \%20Silva.pdf.

Stazzone, R. (1997). O que um psicanalista deve fazer na escola? Estilos da Clinica, 2(2), 44-52. Recuperado de http://pepsic.bvsalud.org/scielo.php?script=sci_arttext\&pid=S141571281997000200005 . 